\title{
Gamma Knife surgery for brainstem metastases
}

\author{
Clinical article
}

\author{
Yanhe Li, M.D., Desheng Xu, M.D., Zhiyuan Zhang, M.D., YiPei Zhang, M.D., \\ Dong Liv, M.D., Xiaomin Liu, M.D., Ph.D., Guokai Wang, M.D., and Yiguang Lin, M.D. \\ Department of Neurosurgery and Gamma Knife Center, Tianjin Medical University 2nd Hospital, Tianjin, \\ People's Republic of China
}

\begin{abstract}
Object. The goal of this study was to assess neuroimaging and clinical outcomes in patients harboring brainstem metastases that were treated with the Leksell Gamma Knife.

Methods. Twenty-eight patients with brainstem metastases (32 lesions: 8 midbrain, 21 pontine, and 3 medullary) were consecutively treated with GKS. The primary cancer diagnoses in this group included 22 cases of lung cancer, 5 cases of breast cancer, and 1 case of rectal cancer. The median age of the patients was 61 years (range $45-83$ years). The median treated lesion volume was $0.78 \mathrm{~cm}^{3}\left(\right.$ range $\left.0.03-5.6 \mathrm{~cm}^{3}\right)$, and the median GKS margin dose was $16 \mathrm{~Gy}$ (range 12-20 Gy). Overall survival in these patients was calculated using the Kaplan-Meier method.

Results. The median survival time was 9 months after GKS (range 2-32 months). Survival was 39.3\% at 1 year and $10.7 \%$ at 2 years. The tumor control rate in the series was $90.6 \%$ (29 of 32 lesions). Development of peritumoral edema occurred in 1 patient after GKS; 4 months after GKS, the edema disappeared.

Conclusions. Gamma Knife surgery using a median margin dose of 16 Gy is a safe and effective local therapy for patients with brainstem metastases.

(http://thejns.org/doi/abs/10.3171/2012.7.GKS121020)
\end{abstract}

\section{KEY WoRdS • brainstem • brain metastases • Gamma Knife surgery • stereotactic radiosurgery}

$\mathrm{T}$ HE incidence of brain metastases is increasing as survival of patients with cancer becomes more prolonged due to advanced cancer therapy. Brain metastases are the most common intracranial tumor; however, brainstem metastases are relatively uncommon, and account for only 3\% to $7 \%$ of all brain metastases. Open surgery for brainstem metastases is difficult because of the risk of neurological damage. Gamma Knife surgery has been reported to provide benefits to patients with brain metastases; however, few data are available to evaluate the effectiveness of GKS for patients with brainstem metastases. In the present study, we review our experience using GKS to treat brainstem metastases.

\section{Methods}

\section{Characteristics of Patients}

Between September 1995 and December 2008, 32 brainstem metastases in 28 patients were treated with

Abbreviations used in this paper: GKS = Gamma Knife surgery; $\mathrm{WBRT}=$ whole brain radiation treatment. the Leksell Gamma Knife (Elekta AB) at our center. The median age of the patients at the time of GKS for brainstem metastases was 61 years (range $45-83$ years). The Karnofsky Performance Scale score ranged from $50 \%$ to $100 \%$ (median 80\%). According to the Radiation Therapy Oncology Group's Recursive Partitioning Analysis, ${ }^{2}$ 3 patients were in Class I, 18 patients were in Class II, and 7 patients were in Class III. The primary malignancies included 22 cases of lung cancer, 5 cases of breast cancer, and 1 case of rectal cancer. Of all 32 lesions, 8 lesions were located in the midbrain, 21 in the pons, and 3 in the medulla oblongata. At the time of GKS, 5 patients presented with a single brainstem metastasis and the other 23 presented with metastatic lesions elsewhere in the brain. Four patients were treated for 2 brainstem metastases. None of the 28 patients had received WBRT previously. Table 1 summarizes clinical characteristics in the 28 patients.

\section{Gamma Knife Surgery}

After a local anesthetic agent had been applied to the patient's head, the stereotactic head frame was af- 
TABLE 1: Characteristics in 28 patients with brainstem metastases*

\begin{tabular}{|c|c|}
\hline Characteristic & Value \\
\hline \multicolumn{2}{|l|}{ sex-no. of patients } \\
\hline male & 18 \\
\hline female & 10 \\
\hline \multicolumn{2}{|l|}{ age (yrs) } \\
\hline median & 61 \\
\hline range & $45-83$ \\
\hline \multicolumn{2}{|c|}{ location of lesion-no. of lesions } \\
\hline midbrain & 8 \\
\hline pons & 21 \\
\hline medulla oblongata & 3 \\
\hline \multicolumn{2}{|c|}{ brain metastases_no. of patients } \\
\hline single brainstem & 5 \\
\hline multiple brain metastases & 23 \\
\hline \multicolumn{2}{|l|}{ KPS score-no. of patients } \\
\hline$>70$ & 18 \\
\hline$\leq 70$ & 10 \\
\hline \multicolumn{2}{|l|}{ RPA class-no. of patients } \\
\hline I & 3 \\
\hline II & 18 \\
\hline III & 7 \\
\hline \multicolumn{2}{|l|}{ primary cancer-no. of patients } \\
\hline lung & 22 \\
\hline breast & 5 \\
\hline rectal & 1 \\
\hline \multicolumn{2}{|l|}{ radiation dose (Gy) } \\
\hline median & 16 \\
\hline range & 12-20 \\
\hline \multicolumn{2}{|l|}{ tumor volume $\left(\mathrm{cm}^{3}\right)$} \\
\hline median & 0.783 \\
\hline range & $0.03-5.6$ \\
\hline
\end{tabular}

* KPS = Karnofsky Performance Scale; RPA = Recursive Partitioning Analysis.

fixed. Gadolinium-enhanced T1-weighted MR images, obtained with a slice thickness of 2-3 mm and no gap, were used to determine the target coordinates and treatment planning. The procedure was performed using the Leksell Gamma Knife model B or model C. The median tumor volume was $0.783 \mathrm{~cm}^{3}$ (range $0.03-5.6 \mathrm{~cm}^{3}$ ). The median tumor margin dose was 16 Gy (range 12-20 Gy), and the median isodose line was 50\% (range 45\%-90\%). We used the GammaPlan system (Elekta $\mathrm{AB}$ ) for GKS treatment planning. Patients received a single intravenous dose of dexamethasone (5-10 mg) or methylprednisolone (40-80 mg) before GKS.

\section{Follow-Up Examinations}

Follow-up MR imaging and clinical examinations were performed every 1-3 months after GKS. Overall survival outcomes were calculated from the date of GKS by using the Kaplan-Meier method.

Follow-up MR images were compared with pre-GKS images. Lesions were measured in the transverse, anteroposterior, and vertical dimensions. Half of the prod- uct of these three diameters was used as a surrogate for tumor volume. A complete response was defined as the disappearance of the treated lesion, a partial response as shrinkage of over $50 \%$ of the tumor volume, and progressive disease as more than $25 \%$ increase of the tumor volume. All else was considered stable disease. Local control was defined as stabilization or improvement of the treated lesion: complete response, partial response, or stable disease.

\section{Results}

\section{Survival Time}

At the time of the analysis, all patients who had undergone GKS had died. The median survival time was 9 months after GKS (range 2-32 months) (Fig. 1). Survival was $67.9 \%, 39.3 \%$, and $10.7 \%$ at 6 months, 1 year, and 2 years, respectively. The cause of death was documented in all 28 patients. One patient (3.6\%) died of recurrent brainstem metastases, and 8 patients $(28.6 \%)$ died of other non-brainstem metastases (7 patients died of new growth of brain metastases and 1 patient of recurrent nonbrainstem metastases). Nineteen patients (67.9\%) died of systemic disease progression.

\section{Tumor Control}

After GKS, follow-up MR images showed shrinkage of the enhancing lesion in 26 brainstem metastases $(81.2 \%)$ (a complete response in 7 lesions and a partial response in 19 lesions) and stable disease in 3 brainstem lesions (9.4\%). In 3 cases (9.4\%), tumor progression was observed at 2, 6, and 10 months. Tumor control in the series was $90.6 \%$ (29 of 32 lesions) (Fig. 2).

\section{Complications}

A complication was observed in only 1 case (Fig. 3). The patient was a 73-year-old man who harbored a brain-

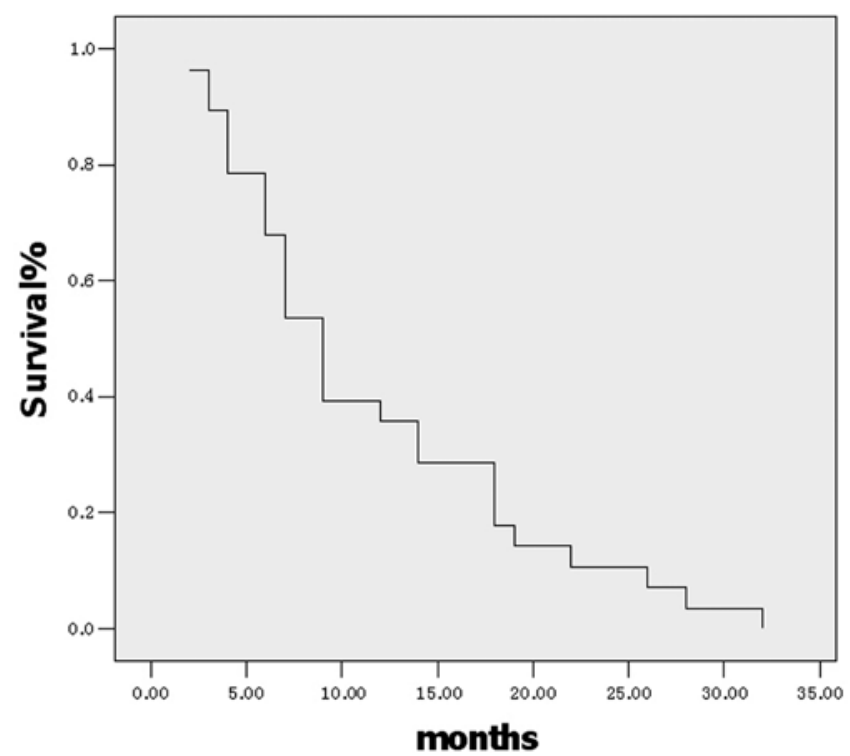

Fıg. 1. Kaplan-Meier plot showing overall survival for all patients from the time of GKS. 


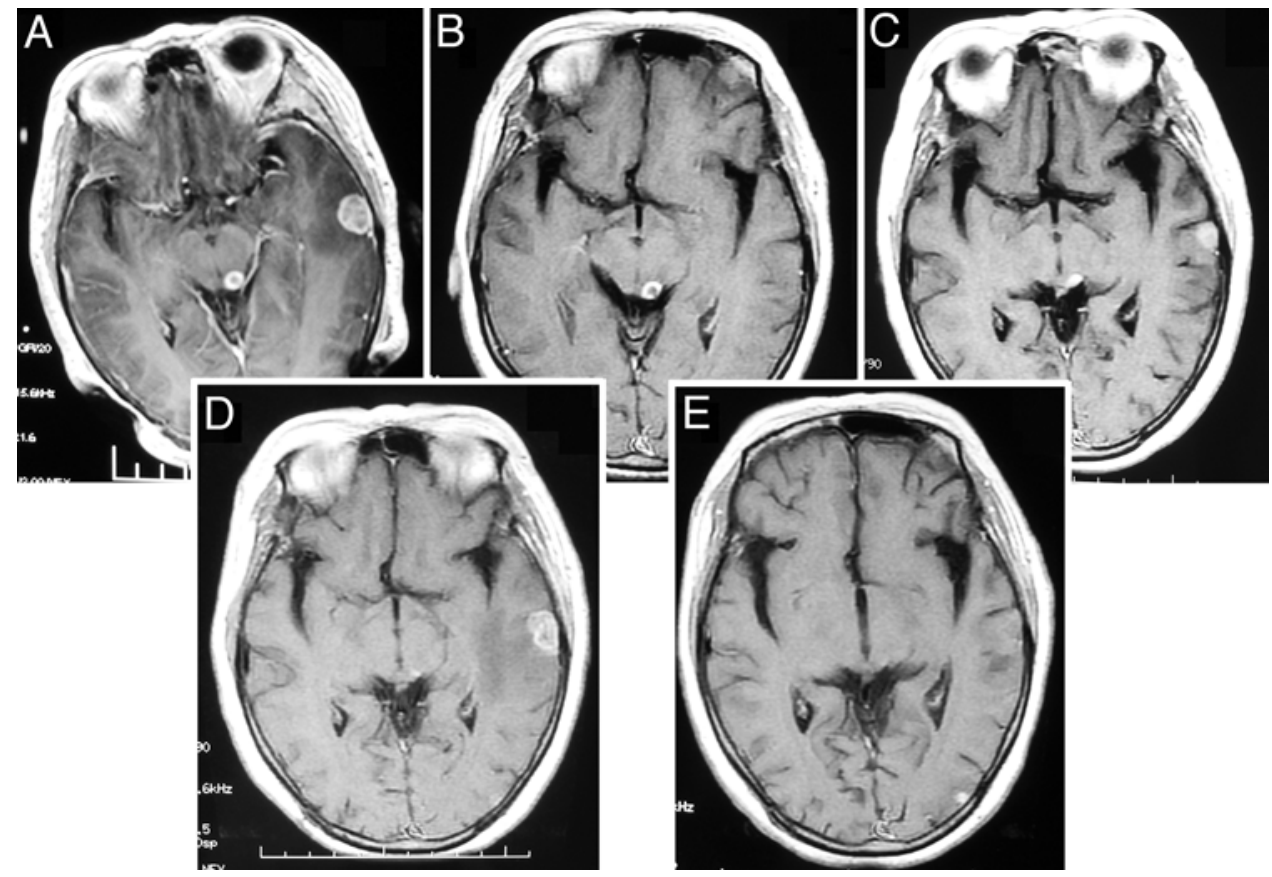

FIG. 2. Axial Gd-enhanced T1-weighted MR images obtained in a patient with a metastatic lesion in the midbrain; the primary disease in this patient was lung cancer. The lesion was treated radiosurgically with a margin dose of $20 \mathrm{~Gy}$. A: Before GKS. B: Three months after GKS. C: At 3 months after GKS, the brainstem lesion has shrunk. D: Twelve months after GKS. E: At 16 months after GKS, the brainstem lesion has disappeared.

stem metastasis in the pons; the metastatic lesion was an offshoot of lung cancer. The lesion was treated radiosurgically with a margin dose of $16 \mathrm{~Gy}$. One month following treatment, the lesion remained stable, but development of peritumoral edema occurred. On the subsequent MR imaging study, obtained 3 months later, the brainstem lesion had diminished in size and the peritumoral edema had disappeared. In the current study, no other radiation-induced toxicity was observed.

\section{Discussion}

Brainstem metastases are relatively rare and have been considered lesions that herald a poor prognosis. Surgery is generally not considered for brainstem metastases.
In patients with brain metastasis, GKS has been shown to provide excellent local control and survival times. It has been widely accepted that radiosurgical doses for brain metastases range from 15 to $24 \mathrm{~Gy}$ in a single treatment. Taking into account that GKS can be more dangerous in patients with brainstem metastases, in our study we delivered a lower prescribed margin dose, ranging from 12 to $20 \mathrm{~Gy}$ (median $16 \mathrm{~Gy}$, approximately a $20 \%$ dose reduction). Most authors have used lower doses for the treatment of brainstem metastases. ${ }^{3-5,9-11}$ The most commonly prescribed median dose for brainstem metastases is $16 \mathrm{~Gy},{ }^{3-5,11}$ which is consistent with the dose delivered in our study.

Lorenzoni et al. ${ }^{8}$ found a correlation between brainstem tumor volume and margin dose: larger lesions are
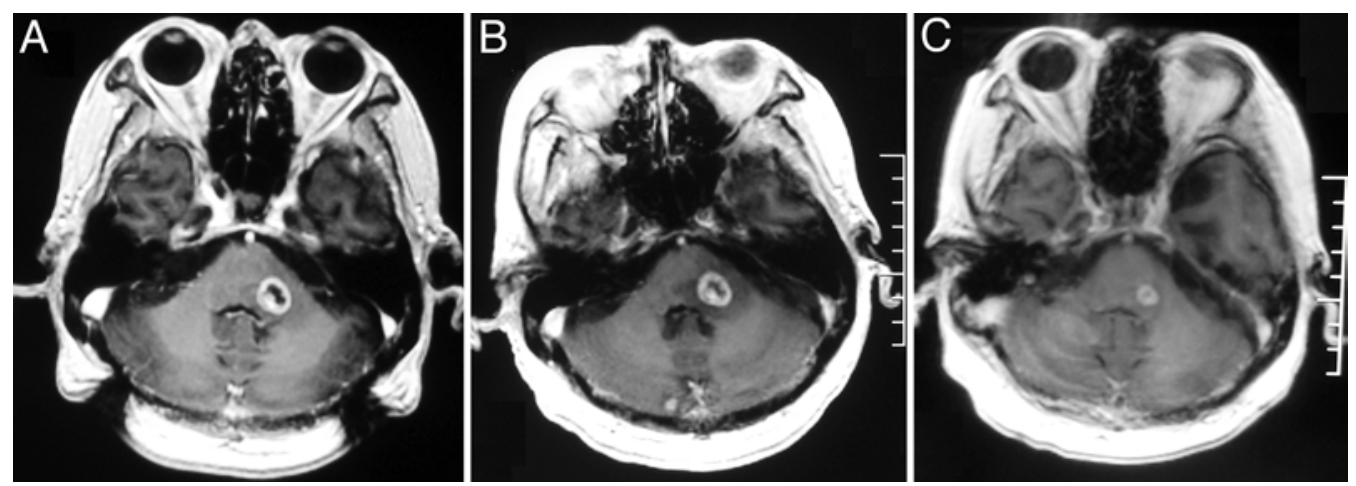

FIG. 3. Axial Gd-enhanced T1-weighted MR images obtained in a patient with a brainstem metastastic lesion in the pons; the primary disease in this patient was also lung cancer. The lesion was treated radiosurgically with a margin dose of $16 \mathrm{~Gy}$. A:

C: At 4 months after GKS, the brainstem lesion has shrunk and the peritumoral edema has disappeared. 
treated with lower prescribed doses. Moreover, Yen et al. ${ }^{10}$ and Lorenzoni et al. ${ }^{8}$ noted that the prescribed dose may need to be reduced for patients who have received WBRT previously. In our study, no patients had received WBRT before GKS. In view of the fact that GKS is more dangerous when treating metastases in the medulla oblongata than it is when treating lesions in the pons and midbrain, in this study we treated lesions in the medulla oblongata with a prescribed margin dose of only $12 \mathrm{~Gy}$.

From 1999 to 2011, there were about 9 published studies on GKS for brainstem metastases..$^{1,3-5,7-11}$ In those studies, the authors reported local control rates ranging from $77 \%$ to $100 \%$, median or mean survival times ranging from 4.9 to 12 months, and GKS-related complications ranging from $0 \%$ to $11 \%$. Patient outcomes were consistent with results reported for brain metastases in other locations. According to most previous studies, the most important predictor of survival after GKS is the extent and management of extracranial disease; this finding applies not only to brainstem metastases but also to metastases in other brain locations. ${ }^{6}$

In the present study the median prescribed dose was $16 \mathrm{~Gy}$, the local control rate was $90.6 \%$, and the median survival time was 9 months, all of which are consistent with data from other published series. In the earliest study on GKS for brainstem metastases, Huang et al. ${ }^{3}$ reported that a median prescribed dose of 16 Gy could achieve a crude local control rate of $95 \%$ and a median survival time of 9 months. Yoo et al. ${ }^{11}$ noted a local tumor control rate of $87.5 \%$ (21 of 24 tumors) and a mean survival of 7.7 months (range 1-22 months). In three of their cases, tumor progression was observed at 6,8, and 16 months. Hussain et al. ${ }^{4}$ used a median tumor margin dose of $16 \mathrm{~Gy}$ (range 14-23 Gy). Median survival time after GKS was 8.5 months, and local tumor control was achieved in all patients in whom follow-up imaging was conducted.

One complication-peritumoral edema-was observed in only 1 patient in our study. Edema occurred 1 month after GKS and disappeared 4 months after GKS. Complications of GKS for brainstem metastases include the following: intratumoral hemorrhage, radionecrosis, ataxia, vomiting, weakness, dysequilibrium, paresthesia, hemiparesis, and seizures, among others. ${ }^{3,5,7}$ Previous studies have reported complication rates ranging from $0 \%$ to $11 \%$ after GKS for brainstem metastases-rates that are similar to the toxicity of GKS for brain metastases outside the brainstem. However, Grade 3 and 4 toxicities were uncommon in most published studies.

\section{Conclusions}

Gamma Knife surgery performed using a median margin dose of $16 \mathrm{~Gy}$ is a safe and effective local therapy for patients with brainstem metastases. Brainstem metastases located in the medulla oblongata, those treated with WBRT previously, and those with large tumor volumes should be treated with a lower prescribed margin radiation dose than other lesions.

\section{Disclosure}

The authors report no conflict of interest concerning the materials or methods used in this study or the findings specified in this paper.

Author contributions to the study and manuscript preparation include the following. Conception and design: Xu. Acquisition of data: $\mathrm{Xu}, \mathrm{Li}, \mathrm{D}$ Liu, Wang. Analysis and interpretation of data: Xu, Li. Drafting the article: Li. Critically revising the article: all authors. Reviewed submitted version of manuscript: all authors. Approved the final version of the manuscript on behalf of all authors: $\mathrm{Xu}$. Statistical analysis: Li, Zhang. Administrative/technical/material support: Lin. Study supervision: Lin.

\section{References}

1. Fuentes S, Delsanti C, Metellus P, Peragut JC, Grisoli F, Regis $\mathrm{J}$ : Brainstem metastases: management using gamma knife radiosurgery. Neurosurgery 58:37-42, 2006

2. Gaspar L, Scott C, Rotman M, Asbell S, Phillips T, Wasserman $\mathrm{T}$, et al: Recursive partitioning analysis (RPA) of prognostic factors in three Radiation Therapy Oncology Group (RTOG) brain metastases trials. Int J Radiat Oncol Biol Phys 37:745-751, 1997

3. Huang CF, Kondziolka D, Flickinger JC, Lunsford LD: Stereotactic radiosurgery for brainstem metastases. J Neurosurg 91:563-568, 1999

4. Hussain A, Brown PD, Stafford SL, Pollock BE: Stereotactic radiosurgery for brainstem metastases: survival, tumor control, and patient outcomes. Int J Radiat Oncol Biol Phys 67:521524,2007

5. Kased N, Huang K, Nakamura JL, Sahgal A, Larson DA, McDermott MW, et al: Gamma knife radiosurgery for brainstem metastases: the UCSF experience. J Neurooncol 86:195-205, 2008

6. Kondziolka D, Martin JJ, Flickinger JC, Friedland DM, Brufsky AM, Baar J, et al: Long-term survivors after gamma knife radiosurgery for brain metastases. Cancer 104:2784-2791, 2005

7. Koyfman SA, Tendulkar RD, Chao ST, Vogelbaum MA, Barnett GH, Angelov L, et al: Stereotactic radiosurgery for single brainstem metastases: the Cleveland Clinic experience. Int J Radiat Oncol Biol Phys 78:409-414, 2010

8. Lorenzoni JG, Devriendt D, Massager N, Desmedt F, Simon $\mathrm{S}$, Van Houtte P, et al: Brain stem metastases treated with radiosurgery: prognostic factors of survival and life expectancy estimation. Surg Neurol 71:188-196, 2009

9. Shuto T, Fujino H, Asada H, Inomori S, Nagano H: Gamma knife radiosurgery for metastatic tumours in the brain stem. Acta Neurochir (Wien) 145:755-760, 2003

10. Yen CP, Sheehan J, Patterson G, Steiner L: Gamma knife surgery for metastatic brainstem tumors. J Neurosurg 105:213219, 2006

11. Yoo TW, Park ES, Kwon H, Kim CJ: Gamma knife radiosurgery for brainstem metastasis. J Korean Neurosurg Soc 50:299-303, 2011

Manuscript submitted May 18, 2012.

Accepted July 24, 2012.

Please include this information when citing this paper: DOI: 10.3171/2012.7.GKS121020.

Address correspondence to: Desheng Xu, M.D., 23 Pingjiang Road, Hexi District, Tianjin, 300211, China. email: tjxudesheng@ 163.com. 